\title{
An update on Burkitt lymphoma: a review of pathogenesis and multimodality imaging assessment of disease presentation, treatment response, and recurrence
}

Kevin Kalisz ${ }^{1}$, Francesco Alessandrino ${ }^{2,3^{*}}$, Rose Beck ${ }^{4}$, Daniel Smith ${ }^{5}$, Elias Kikano ${ }^{5}$, Nikhil H. Ramaiya ${ }^{5}$ and Sree Harsha Tirumani $i^{2,3,5}$

\begin{abstract}
Burkitt lymphoma (BL) is a highly aggressive, rapidly growing B cell non-Hodgkin lymphoma, which manifests in several subtypes including sporadic, endemic, and immunodeficiency-associated forms. Pathologically, BL is classically characterized by translocations of chromosomes 8 and 14 resulting in upregulation of the c-myc protein transcription factor with upregulation of cell proliferation. BL affects nearly every organ system, most commonly the abdomen and pelvis in the sporadic form. Imaging using a multimodality approach plays a crucial role in the management of $\mathrm{BL}$ from diagnosis, staging, and evaluation of treatment response to therapy-related complications with ultrasound, computed tomography, magnetic resonance imaging, and positron emission tomography playing roles. In this article, we review the pathobiology and classification of BL, illustrate a multimodality imaging approach in evaluating common and uncommon sites of involvement within the trunk and head and neck, and review common therapies and treatment-related complications.
\end{abstract}

Keywords: Burkitt lymphoma, Lymphoma, B cell, Diagnostic imaging, Computed tomography, Drug therapy

\section{Key points}

- Burkitt lymphoma can be differentiated from other forms of diffuse large B cell lymphoma based on underlying pathobiology, which is reflected in the updated WHO classification.

- Radiologists should recognize common and uncommon presentations and sites of disease to appropriately guide clinicians given the urgency of potential of treatment.

- Multiple imaging modalities play a key role in Burkitt lymphoma evaluation throughout the entire disease course, each with advantages and disadvantages.

\footnotetext{
* Correspondence: falessandrino@bwh.harvard.edu

2Department of Imaging, Dana Farber Cancer Institute, Harvard Medical School, 450 Brookline Avenue, Boston, MA 02215, USA

${ }^{3}$ Department of Radiology, Brigham and Women's Hospital, Harvard Medical School, Boston, MA, USA

Full list of author information is available at the end of the article
}

\section{Introduction}

Burkitt lymphoma (BL) is a highly aggressive B cell non-Hodgkin lymphoma (NHL) characterized by the translocation and deregulation of the $M Y C$ gene on chromosome 8 with the potential to involve multiple organ systems. Three subtypes of BL (sporadic, endemic, and immunodeficiency-associated) are recognized with different epidemiology, risk factors, and clinical presentations.

The sporadic subtype of BL is generally observed in the USA and Western Europe with an overall incidence of three cases per million persons per year in the general population. Sporadic BL is relatively more common in the pediatric population, accounting for $30 \%$ of pediatric lymphomas with a peak incidence around the age of 10 years old, while only representing less than $1 \%$ of NHL in adults $[1,2]$. Sporadic cases are associated with Epstein-Barr virus (EBV), and the most common site of involvement is within the abdomen, particularly the 
bowel [3]. The sporadic subtype will be the focus of this article.

The endemic subtype is found in equatorial Africa and New Guinea with a near 50-fold higher incidence than that seen in the USA [4]. Endemic BL accounts for up to $50 \%$ of all childhood cancer in equatorial Africa with an estimated incidence of 3 to 6 cases per 100,000 children per year [5]. The most common presentation is a facial tumor, and nearly all cases are associated with EBV [6]. Immunodeficiency-associated BL is mostly commonly seen in HIV-positive patients, but also may be seen in allograft recipients and patients with congenital immunodeficiency. HIV patients with $\mathrm{BL}$ tend to have relatively higher CD4 counts $(>200$ cells $/ \mu \mathrm{L})$ and the majority demonstrate EBV positivity. The most common sites of involvement are lymph nodes, bone marrow, and the central nervous system (CNS) [3].

$\mathrm{BL}$ exhibits very heterogeneous presentations and clinical courses among patients. In this article, we review the pathogenesis and classification of $\mathrm{BL}$, illustrate a multimodality imaging approach in evaluating common and uncommon sites of involvement, and highlight important treatment topics.

\section{Pathology and classification}

\section{Pathogenesis and histologic features}

BL is derived from germinal center B cells. The three clinical subtypes of BL are thought to arise from B cells at different stages of their development. BL development depends on expression of MYC gene, which encodes for the c-myc protein transcription factor, which is located on chromosome 8q24 and regulates cell proliferation, differentiation, and apoptosis.
BL is characterized by inappropriately high levels of c-myc, which can result via several different mechanisms, most commonly by translocation of the long arm of chromosome 8 (containing the $M Y C$ gene) and the Ig heavy chain gene on chromosome 14. c-Myc overexpression leads to rapid $\mathrm{B}$ cell proliferation accounting for the rapid doubling time of BL tumor cells (between 24 and 48 h) [7]. Histologically, BL demonstrates a "starry sky" appearance with benign histiocytes containing abundant, clear cytoplasm dispersed among a background of homogeneous, basophilic tumor cells. Markedly high rates of both proliferation and apoptotic cell death are generally observed [8].

Related but distinct pathologic entities are lymphomas demonstrating "double" or "triple-hit" phenomena accounting for $3-10 \%$ of diffuse large B cell lymphomas (DLBCL). "Double hit" lymphomas are characterized by the presence of both $M Y C$ and $B C L-2$ (or less commonly $B C L-6$ ) rearrangements, while "triple-hit" lymphomas demonstrate $M Y C$, $B C L-2$, and $B C L-6$ rearrangements. These lymphoma subtypes exhibit further inhibition of apoptosis and cell survival and are associated with poorer prognosis. Multiple hit lymphomas should be distinguished from "double expressor" DLBCLs in which $M Y C$ and $B C L-2$ genes are overexpressed at the protein level without the genetic rearrangements [9].

\section{WHO classification}

In the 2016 World Health Organization (WHO) classification of lymphoid neoplasms, aggressive B cell lymphomas, which includes $\mathrm{BL}$, have undergone revision now accounting for both tumor morphology and genetics [10]. Initial immunohistochemical or gene expression

Table 1 Utility of PET in Burkitt lymphoma

\begin{tabular}{|c|c|c|}
\hline $\begin{array}{l}\text { Study (year } \\
\text { published) }\end{array}$ & $\begin{array}{l}\text { Patient population (cohort } \\
\text { size) }\end{array}$ & Utility \\
\hline $\begin{array}{l}\text { Albano et al. } \\
\text { (2018) [16] }\end{array}$ & Adults $(n=65)$ & $\begin{array}{l}\text {-End of treatment PET/CT results significantly correlate with PFS and OS } \\
\text {-Interim PET/CT did not correlate with PFS and OS }\end{array}$ \\
\hline $\begin{array}{l}\text { Albano et al. } \\
(2019)[17]\end{array}$ & Adults $(n=65)$ & $\begin{array}{l}\text {-Total metabolic tumor volume and total lesion glycolysis independent } \\
\text { prognostic factors for PFS and OS }\end{array}$ \\
\hline $\begin{array}{l}\text { Bailly et al. } \\
\text { (2014) [18] }\end{array}$ & Children $(n=19)$ & $\begin{array}{l}\text {-Significantly higher NPV of PET (93\%) compared to conventional imaging (73\%) in detecting } \\
\text { CR } \\
\text {-PFS significantly higher in patients with negative PET than those with positive PET }\end{array}$ \\
\hline $\begin{array}{l}\text { Carrillo-Cruz et al. } \\
(2015)[19]\end{array}$ & Adults and children $(n=32)$ & $\begin{array}{l}-100 \% \text { NPV in predicting CR } \\
-100 \% \text { PPV of nonresponse with SUV change }<66 \% \text { after treatment }\end{array}$ \\
\hline $\begin{array}{l}\text { Davidson et al. } \\
\text { (2018) [20] }\end{array}$ & Adults $(n=20)$ & $\begin{array}{l}\text {-Increased splenic FDG uptake rarely involved at time of staging } \\
\text {-Low rate of spleen involvement may serve as a specific characteristic of BL }\end{array}$ \\
\hline $\begin{array}{l}\text { Karantanis et al. } \\
(2010)[21]\end{array}$ & Adults and children $(n=15)$ & $\begin{array}{l}\text {-High sensitivity (100\%) and specificity (94-96\%) for detection of nodal and extranodal } \\
\text { disease }\end{array}$ \\
\hline $\begin{array}{l}\text { Wei et al. } \\
(2015)[22]\end{array}$ & Adults $(n=29)$ & $\begin{array}{l}\text {-Significant reduction in SUV } \text { max }_{\text {maring interim and post-therapy PET/CTS }} \\
\text {-SUV decease }>50 \% \text { after post-therapy PET/CT was a favorable cutoff point to predict OS }\end{array}$ \\
\hline
\end{tabular}

PFS progression-free survival, OS overall survival, NPV negative predictive value, $P P V$ positive predictive value, $C R$ complete response 
studies are performed to confirm a germinal center B cell-based cell origin. Further immunophenotype testing specific for $\mathrm{BL}$ and identification of $M Y C$ overexpression supports the identification of BL. However, it has been shown that some aggressive lymphoma subtypes demonstrate features overlapping $\mathrm{BL}$ and other DLBCLs, which had been previously classified as B cell lymphoma, unclassifiable. In the 2016 WHO classification, this category has been eliminated and replaced by the category "high-grade B cell lymphoma, with $M Y C$ and $B C L-2$ and/or BCL-6 rearrangements", which encompasses "double" and "triple-hit" lymphomas. Additionally, entities previously falling into a "Burkitt-like" lymphoma category (i.e., aggressive B cell lymphoma entities resembling BL) are classified into either high-grade B cell lymphoma with $M Y C$ and $B C L-2$ and/or $B C L-6$ rearrangement, Burkitt-like lymphoma with $11 \mathrm{q}$ aberration, or high-grade $\mathrm{B}$ cell lymphoma, not otherwise specified. Notably, the double-expresser is not considered in these categories but is recognized as a poor prognostic sign within DLBCL.

\section{Imaging evaluation}

Although the diagnosis of BL is confirmed pathologically by characteristic biology, immunophenotype, and genetic analysis, imaging plays a critical role throughout the entire clinical course of these patients from initial detection, including emergent presentations, to evaluating treatment response and potential complications. Various modalities are employed in the assessment of BL, each with particular strengths and weaknesses.

For patients presenting in an emergent setting with acute symptoms, either ultrasound or computed tomography $(\mathrm{CT})$ is often utilized. Ultrasound is particularly useful in the pediatric population given the lack of ionizing radiation. Ultrasound can evaluate for the presence of palpable masses or intussusception in pediatric patients and is well suited to evaluate small and superficial sites of involvement such as peripheral lymph nodes, gonads, thyroid, and breast [11]. Ultrasound is appropriate for the evaluation of lymph node architecture and assessing benign versus malignant nodal features. Ultrasound findings or malignant nodes include loss of an echogenic hilum, asymmetric cortical thickening, distortion of intranodal vascular architecture (i.e., aberrant vessels), and amputated short subcapsular vessels. However, ultrasound may be limited by operator dependence and in its evaluation of deeper abdominal structures, particularly in larger adults. Conversely, CT offers rapid, whole body evaluation (including staging information) with improved soft tissue resolution while overcoming the
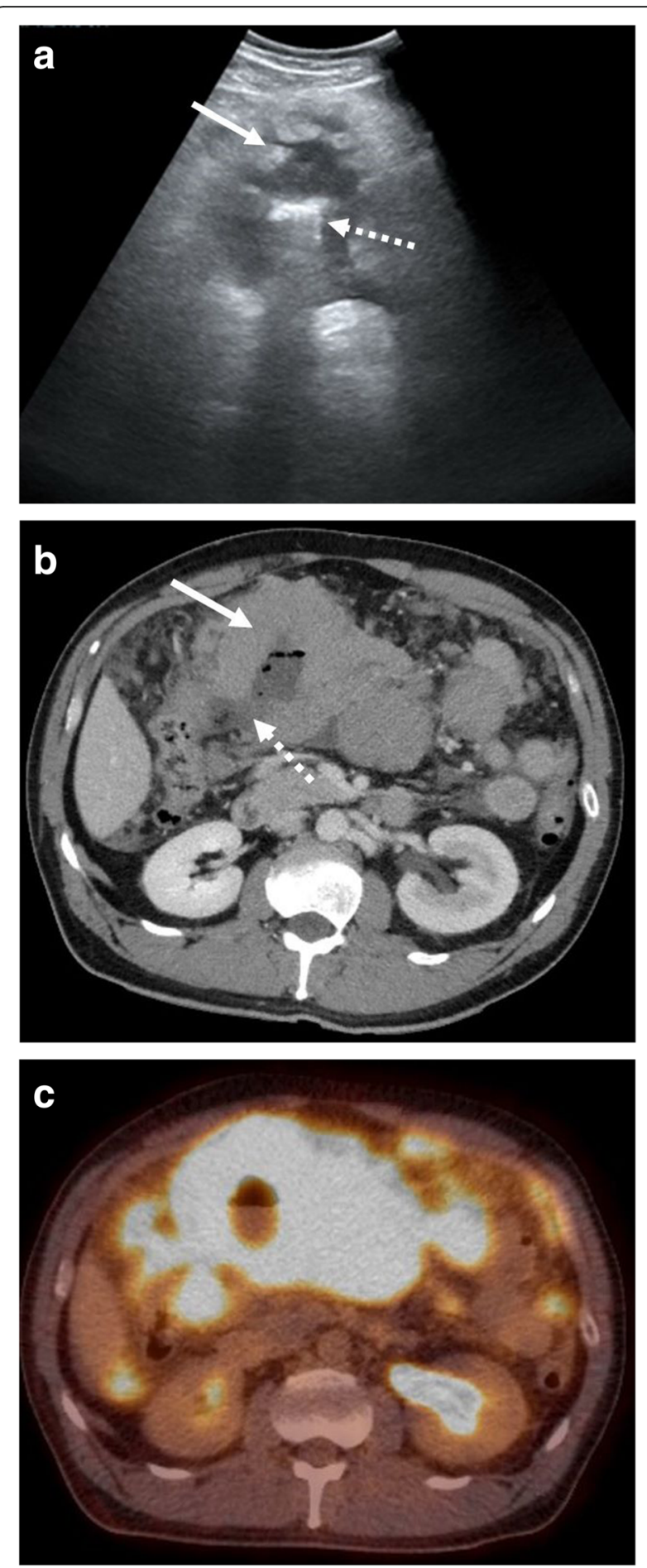

Fig. 1 Bowel involvement with perforation. A 49-year-old male presenting to the emergency department with abdominal pain. a Transverse grayscale ultrasound image demonstrates mass-like thickening of a bowel loop within the mid-abdomen (solid arrow) with central air and associated dirty shadowing (dashed arrow). b Subsequently performed axial $C T$ shows a large central mass (solid arrow) with associated perforation (dashed arrow). c Follow-up fused axial PET-CT demonstrates associated hypermetabolic activity and extensive background abdominal disease. Burkitt lymphoma was confirmed at surgery 

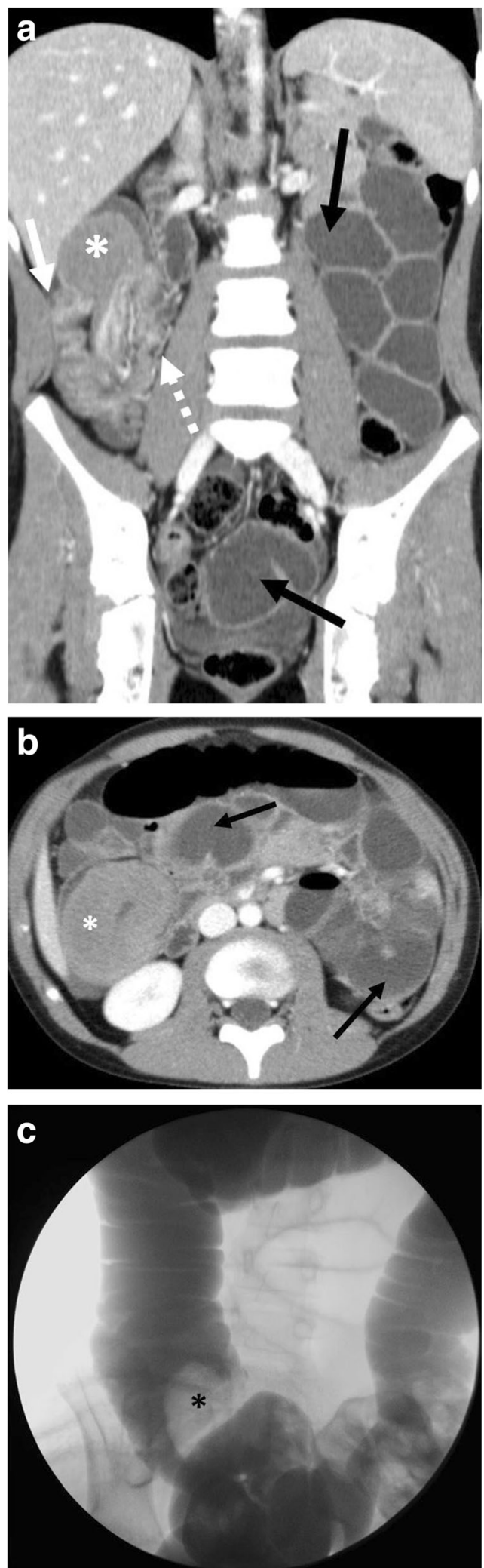

Fig. 2 Bowel involvement with intussusception. A 10-year-old male presenting to the emergency department with abdominal pain. a Coronal and (b) axial contrast enhanced $\mathrm{CT}$ images demonstrate ileo-colic intussusception with intussusceptum (dashed arrow) and intussuscipiens (solid arrow) and dilated, fluid-filled small bowel loops (black arrows) from an associated small bowel obstruction. Lead point mass (asterisks) is also seen. c Subsequent fluoroscopic-guided contrast reduction enema demonstrating filling defect (asterisks) corresponding to the lead point mass was ultimately unsuccessful. The patient underwent surgical resection with pathology demonstrating Burkitt lymphoma

acoustic limitations of ultrasound [12]. Exams are preferably performed with intravenous contrast for better soft tissue evaluation, although poor renal function and allergy may prohibit its use. Multiplanar reformatted images should routinely be used. In the setting of osseous involvement, $\mathrm{CT}$ is adequate to evaluate for bone destruction. A principle disadvantage of CT is ionizing radiation exposure. It should be emphasized that modalities utilizing ionizing radiation should be performed in accordance with the principle of As Low As Reasonably Achievable (ALARA). Furthermore, interpretation of CT in some pediatric patients may be difficult in the setting of absent intra-abdominal fat planes.

Although not typically employed in the emergency setting, magnetic resonance imaging (MRI) has an increasing role in the evaluation of BL. The strength of MRI is its superior soft tissue characterization, which is of particular value in assessing tumor extension and central nervous system (CNS) involvement. Standard protocols utilize a combination of multiplanar T1- and T2-weighted images, with and without fat saturation, although protocols should be tailored to the anatomy being evaluated. For example, if there is clinical concern for biliary obstruction, magnetic resonance cholangiopancreatography (MRCP) can be obtained. Although data specific to Burkitt lymphoma is lacking, the addition of diffusion-weighted imaging (DWI) has demonstrated added value over conventional sequences by increasing lesion conspicuity and improving accuracy of initial diagnosis in other lymphoma subtypes [13]. Furthermore, DWI in lymphoma has shown to correlate with higher cellularity and proliferative index and has shown utility in assessing treatment response [14, 15]. The lack of ionizing radiation is an advantage in assessing pediatric patients, particularly those requiring serial follow-up imaging. However, limitations of MRI include long exam times and relatively limited availability, particularly in emergent settings. 
Positron emission tomography (PET), when combined with $\mathrm{CT}$, offers the advantage of combining functional information with anatomic imaging. There is a growing body of literature evaluating the utility of PET/CT in both pediatric and adult BL patients (Table 1) [16-22]. For example, Carrillo-Cruz et al. demonstrated a high discrepancy rate between $\mathrm{CT}$ and PET/CT with PET/CT achieving a 100\% negative predictive value in predicting treatment response as well $100 \%$ positive predictive values in predicting recurrence using a standardized uptake value (SUV) change threshold less than 66\% [19]. Similarly, Wei et al. showed significant reduction in $\mathrm{SUV}_{\max }$ on interim and post-therapy PET/CT and that changes in $\mathrm{SUV}_{\max }$ greater than $50 \%$ was a favorable cutoff point to predict the overall survival of $\mathrm{BL}$ patients [22]. $\mathrm{PET} / \mathrm{CT}$ may also offer superior staging compared to anatomic imaging such as CT. For example, in the pediatric population, PET/CT has demonstrated better ability to detect both nodal and extranodal sites of disease and greater impact on initial staging compared to CT [23]. PET/MRI has not yet been investigated in BL patients, although has shown similar performance as PET/CT in staging and follow-up in other lymphoma cohorts [24]. PET/MRI can simultaneously combine soft tissue characterization strengths of MRI with the functional assessment of PET. Furthermore, substitution of the CT component with MRI allows for radiation dose savings. However, both PET/CT and PET/MRI are subject to relatively long exams and limited availability, particularly PET/ MRI. Also, PET exams are subject to added radiation exposure.

According to the National Comprehensive Cancer Network (NCCN) guidelines, initial staging in adults should be performed with diagnostic CT of the chest, abdomen, and pelvis [25]. Initial imaging studies in children with BL must include chest radiograph, cervical and abdominal ultrasound, CT of the chest, abdomen, and pelvis. Depending on the clinical presentation, contrast-enhanced neck and/or brain MRI may also be warranted. PET/CT should be performed if it is possible, provided it will not delay treatment, which should be started promptly, given the rapid tumor growth [26]. Also, initial cardiac function evaluation should be performed with either echocardiogram or multi-gated (MUGA) cardiac blood pool scan in anticipation of treatment with an anthracycline or anthracenedione-based regimen. Initial staging PET/CT may be useful, although is not currently routinely recommended, although it should not delay prompt treatment start. Depending on the clinical presentation, contrast-enhanced neck and/or brain MRI may also be warranted. The role of PET/CT
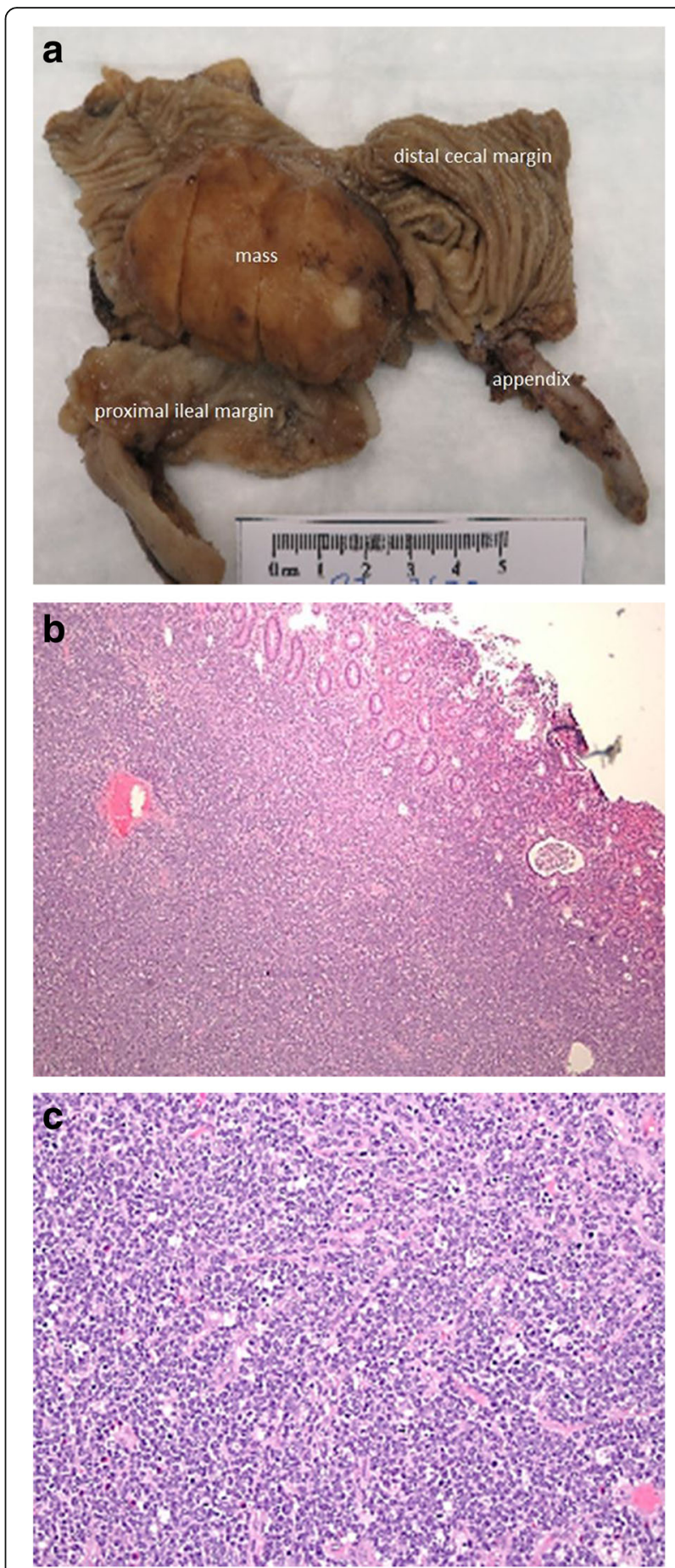

Fig. 3 Pathology findings of Burkitt lymphoma. A 10-year-old male (presented in Fig. 2). a Gross exam shows a $6 \mathrm{~cm}$ firm mass at the ileo-cecal junction. Microscopically, (b) $(\times 40)$ the lymphoma is composed of sheets of monotonous lymphocytes invading the bowel mucosa and cells $(\mathbf{c})(\times 200)$ has a characteristic "starry sky" appearance due to the presence of scattered histiocytes engulfing apoptotic lymphoma 

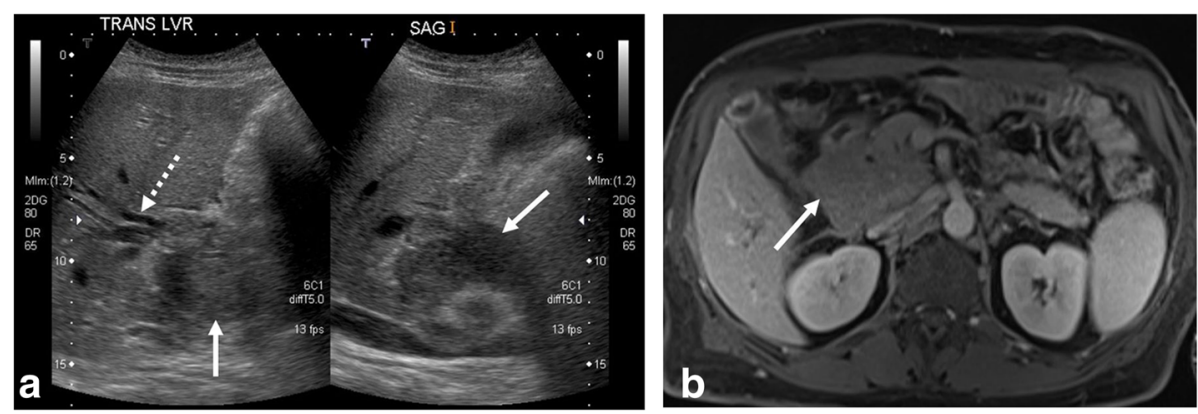

C
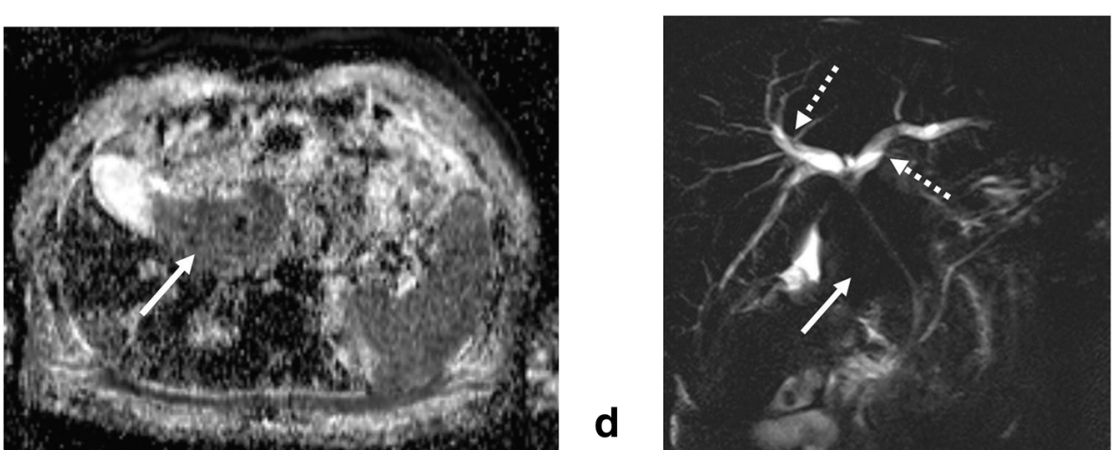

Fig. 4 Nodal mass with biliary obstruction. A 55-year-old male presenting with jaundice. a Initial grayscale transverse and sagittal ultrasound images demonstrate an ill-defined hypoechoic mass near the porta hepatis (solid arrow) with associated biliary dilatation. Follow-up MRI with (b) axial post contrast, (c) apparent diffusion coefficient map, and (d) coronal MRCP images demonstrate an enhancing mass with diffusion restriction (solid arrows) encasing and narrowing the extrahepatic bile ducts causing intrahepatic biliary dilatation (dashed arrow)

imaging prior to completion of therapy has not been well-established. Contrary to evidence demonstrating prognostic value of interim PET/CT in DLBCL, studies to date evaluating this practice in $\mathrm{BL}$ have not shown similar results $[16,22,27]$. If there is a

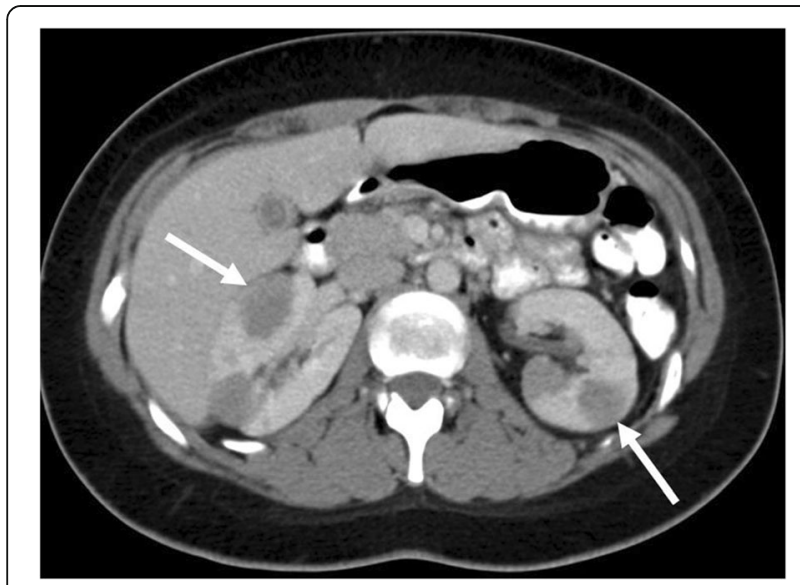

Fig. 5 Renal involvement with renal masses. Contrast-enhanced axial CT image of a 23-year-old female with known Burkitt lymphoma demonstrates multiple circumscribed hypoattenuating renal masses (arrows) concern for relapsed or refractory disease, PET/CT is recommended as the modality of choice.

\section{Imaging findings}

\section{Abdomen and pelvis}

The abdomen is the most common site of involvement of BL. The most frequently involved organ is the small bowel at the ileo-cecal region due to the high concentration of lymphoid tissue. BL of the stomach and appendix are uncommon [28]. BL of the bowel appears as either a focal mass or segmental wall thickening. Wall thickening has been described as aneurysmal, with associated dilation of the lumen. Obstruction, different from other bowel malignancies and masses, is uncommon. Masses communicating with the bowel lumen may demonstrate internal air, which is best appreciated on CT but also may be identified on ultrasound by the presence of "dirty shadowing" (Fig. 1). Intussusception leading to bowel obstruction is a well-documented complication of bowel involvement and reason for emergent presentation, particularly in the pediatric population (Figs. 2 and 3) [29]. On ultrasound, signs of intussusception include concentric alternating echogenic and hypoechoic bands of bowel layers ("target sign") on transverse views and corresponding "pseudokidney" sign on 
longitudinal views. CT demonstrates telescoping bowel with associated mesenteric fat and vessels and better depicts the extent of an upstream bowel obstruction. The $\mathrm{BL}$ mass lead point may or may not be discretely visualized on initial imaging.

BL also presents within the abdomen as mesenteric and retroperitoneal nodes. These may be single or multiple and may grow to conglomerate masses that often encase and grow along major mesenteric vessels with the potential to cause biliary, urinary, or bowel obstruction (Fig. 4) [12]. Ascites is also a potential finding in patients with abdominal involvement [28]. In advanced cases, lymphomatosis may be present appearing as multiple peritoneal nodules. However, isolated involvement of the peritoneum is rare [30].
Although less common than bowel involvement, solid organ involvement in the abdomen and pelvis may also occur [28]. BL of the liver is more often secondary than primary and may appear as single or multiple mass-like or infiltrative areas within the liver. Spleen involvement most commonly manifests as splenomegaly, although may be normal in size. Ultrasound is a useful means of monitoring spleen size, and PET/CT is highly accurate in detecting splenic involvement [31]. BL of the pancreas is uncommon but may present as biliary obstruction in cases involving the pancreatic head. Renal involvement is variable ranging from nephromegaly with striated nephrogram on CT or MRI with diffusely infiltrative disease (most common) or single or multiple discrete renal masses (Fig. 5). BL of the renal collecting system and ureter
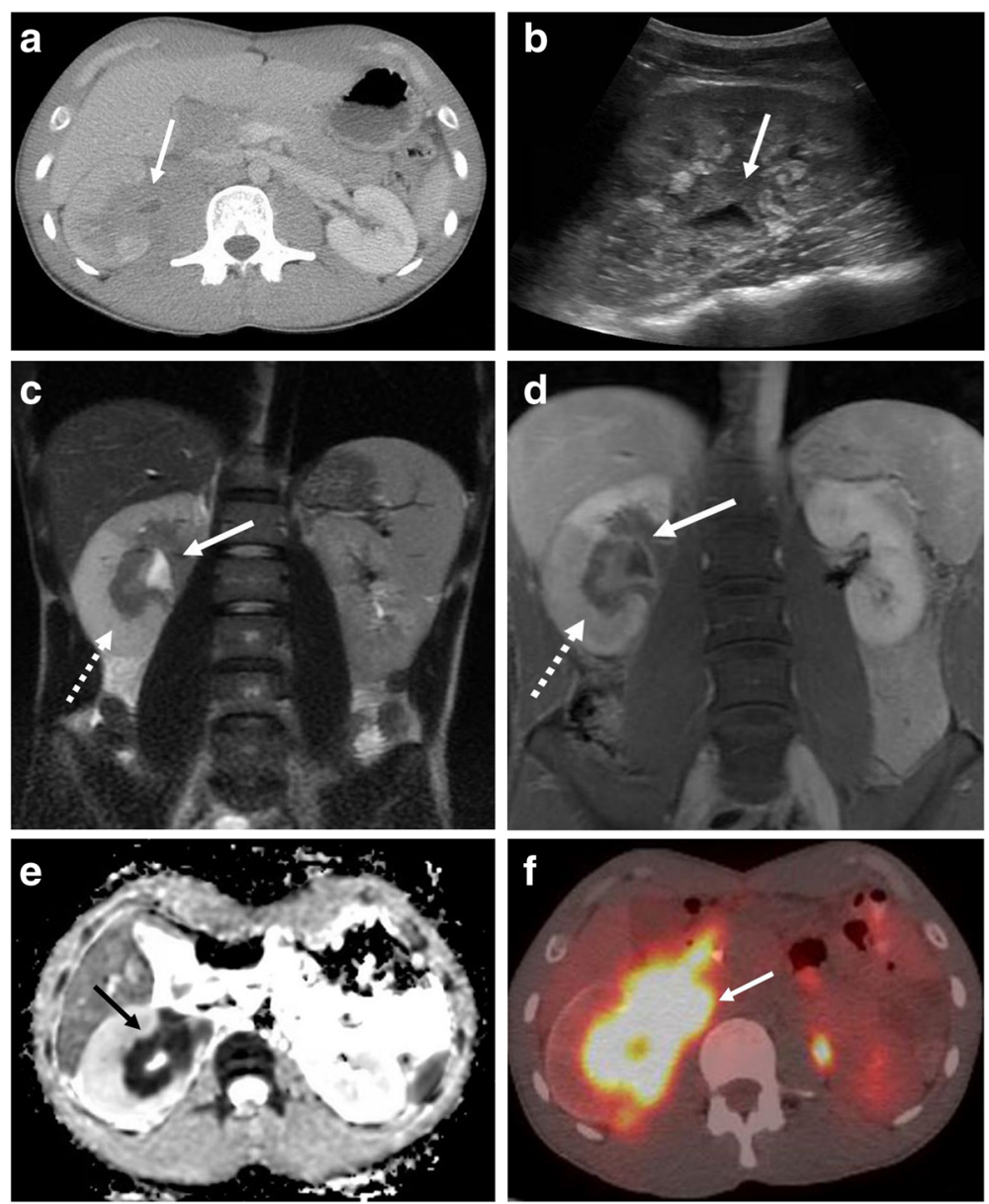

Fig. 6 Renal collecting system involvement. A 24-year-old male presenting with abdominal and lower back pain. a Contrast-enhanced axial CT image demonstrates an infiltrative soft tissue mass (arrow) encasing the right renal collecting system with resultant dilated renal pelvis and urothelial thickening. b Corresponding sagittal grayscale ultrasound image (b) demonstrates obliteration of the normal renal sinus fat by hypoechoic tissue encasing the renal pelvis (arrow). Follow-up MRI with (c) coronal T2-weighted, (d) coronal T1-weighted post contrast, and (e) axial apparent diffusion coefficient images shows a right renal pelvis mass with associated diffusion restriction (solid arrows) with edema and delayed enhancement of portions of the right renal parenchyma (dashed arrows). $\mathbf{f}$ Follow-up fused axial PET-CT demonstrates associated hypermetabolic activity (arrow) 
may present with hydronephrosis and renal failure (Fig. 6). Gonadal involvement is uncommon. In males, $\mathrm{BL}$ of the testicles may present as diffuse testicular enlargement or discrete testicular masses (Fig. 7). The
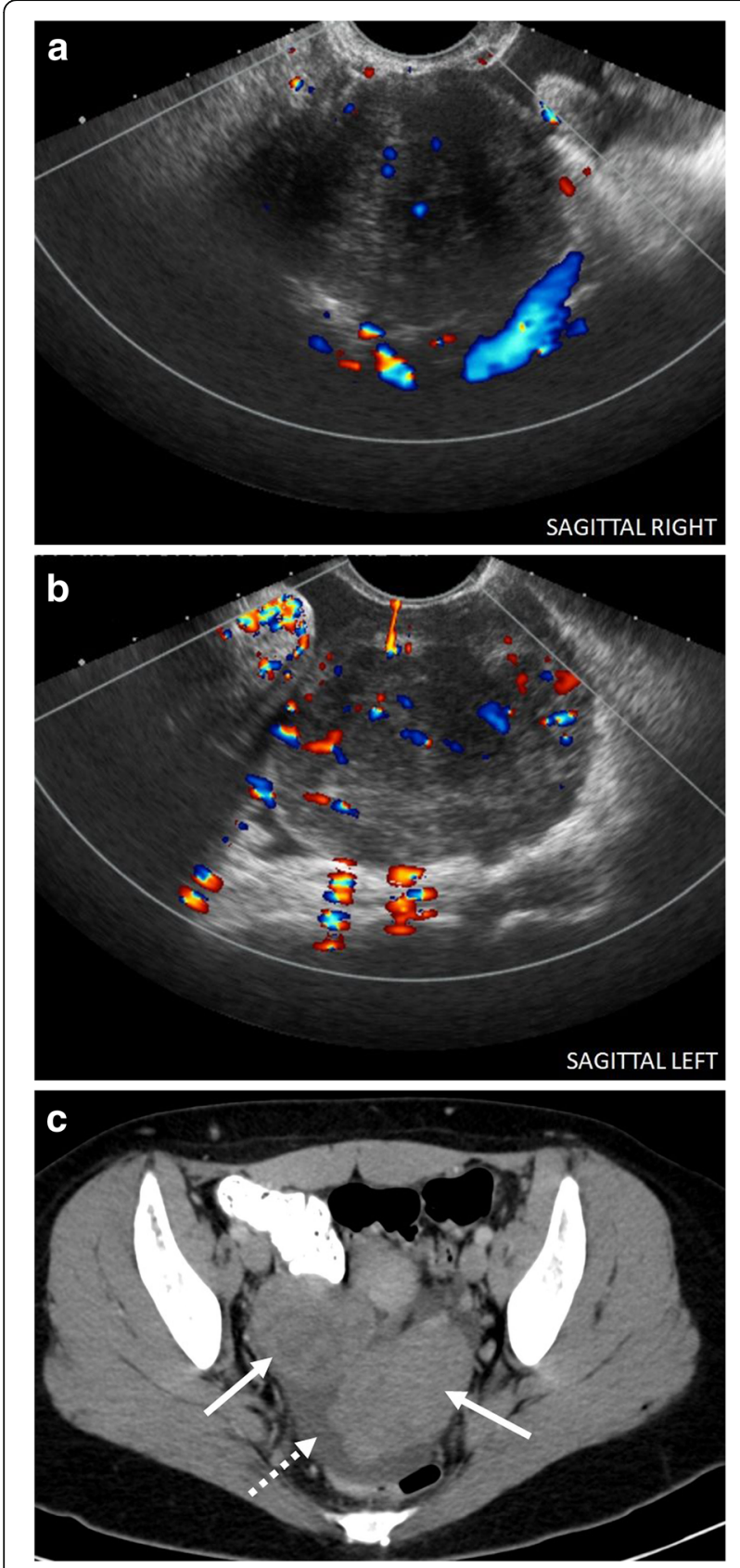

Fig. 7 Bilateral ovarian masses. A 23-year-old female presenting with pelvic pain. Sagittal color Doppler images through the (a) right and (b) left ovaries demonstrate heterogeneous enlargement of the bilateral ovaries containing internal flow, greater on the left. c Subsequent contrast-enhanced CT shows markedly enlarged bilateral ovaries (solid arrows) with adjacent pelvic free fluid (dashed arrow). Subsequent exploratory laparotomy with bilateral salpingo-oophorectomy revealed Burkitt lymphoma epididymis and spermatic cord may also be involved. Appearance of ovarian BL is variable with reports of unilateral or bilateral cystic, solid, or mixed solid and cystic masses (Fig. 8) [12].

\section{Chest}

Thoracic involvement is common and most often manifests with pleural effusion, which can sometimes be massive, causing mediastinal shift [28]. Mediastinal or hilar lymphadenopathy are also seen $[28,32]$. Uncommon intrathoracic manifestations of $\mathrm{BL}$ include pericardial and myocardial involvement, presenting with single or multiple masses, lung parenchymal and endobronchial lesions, and chest wall masses [33-35] (Fig. 9). Pleural disease usually presents as single or multiple pleural-based nodules and masses and may manifest symptomatically with dyspnea in the setting of a pleural effusion. Emergent presentations with cardiac tamponade appearing as a large pericardial effusion with cardiac chamber distortion and signs of reduced cardiac output have been reported with pericardial involvement [36]. BL of the breast is rare and is most commonly described as a rapidly growing, unilateral circumscribed breast mass, although bilateral and diffuse involvement has been reported [37] (Fig. 10).

\section{Head and neck and central nervous system}

Head and neck involvement of BL is the characteristic and most common site of involvement in the endemic form of $\mathrm{BL}$, occurring in up to $50-60 \%$ of cases and presenting clinically as a rapidly enlarging, often painless, jaw mass [38]. In the endemic form, the mandible and other facial bones are involved by osteolytic lesions with bony destruction and possible invasion of adjacent facial compartments such as the orbit. Adjacent nerves may be compromised presenting clinically with facial anesthesia or paresthesia.

Nodal involvement, on the other hand, is more often seen in sporadic BL and appears as mass-like, often heterogeneous, enlargement of the affected nodes. Extranodal structures of the head and neck most likely to be involved in sporadic BL are those of Waldeyer ring, which include the palatine and lingual tonsils and adenoids of the nasopharynx [39]. $\mathrm{BL}$ of the thyroid is rare but may manifest as thyroid nodules sometimes large enough to cause tracheal or neurovascular compression (Fig. 11) [40]. In contrast to endemic BL, nodal and extranodal masses in sporadic BL infiltrate, rather than erode, into adjacent facial compartments. While superficial nodal involvement may be depicted on ultrasound, the full extent of involvement and relationship to surrounding structures is better depicted on MRI and appears relatively 


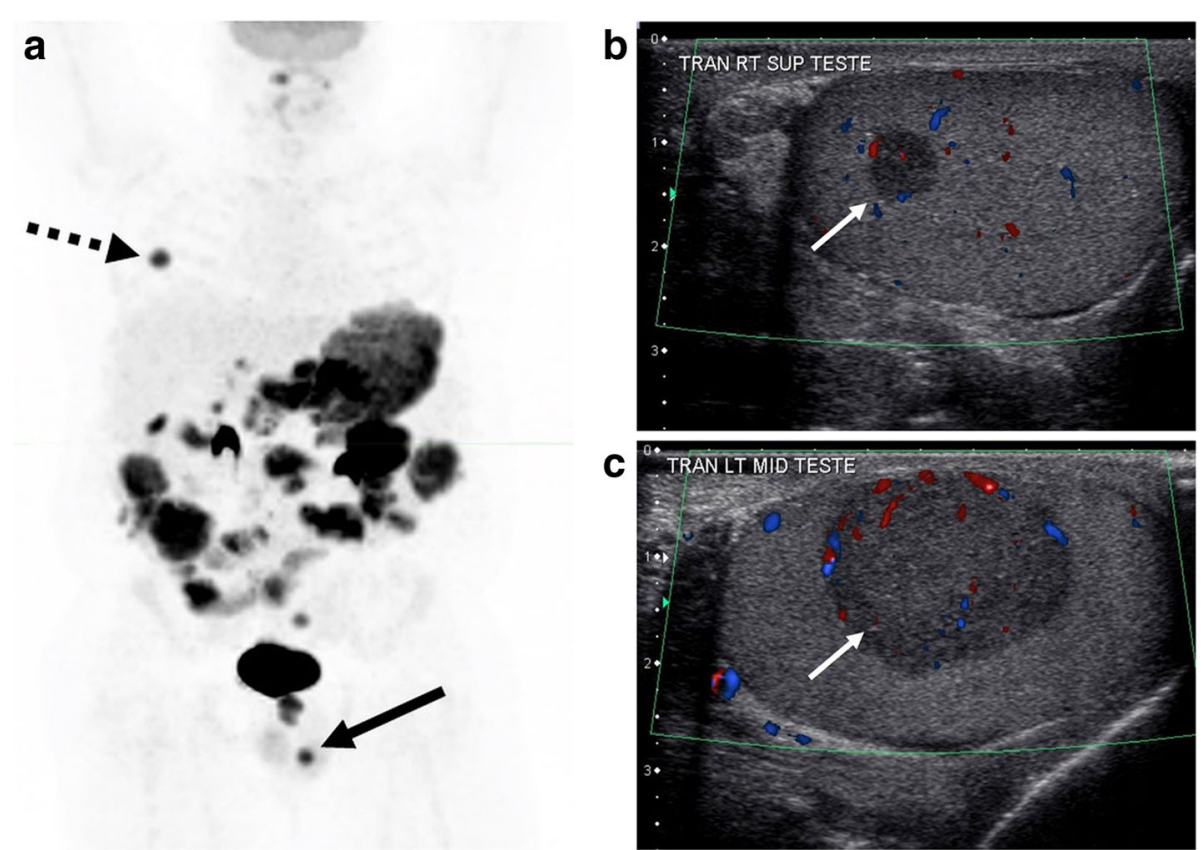

Fig. 8 Bilateral testicular masses. A 39-year-old HIV-positive male with known Burkitt lymphoma. a Whole body planar PET image demonstrates widespread abdominal disease with a small focus of hypermetabolic activity within the region of the left testicle (solid arrow). Less intense, linear activity within the abdomen corresponds to physiologic bowel activity. Small focus of uptake in the right hemithorax (dashed arrow) corresponds to pleural disease. Sagittal color Doppler images through the (b) right and (c) left testicles demonstrate bilateral hypoechoic testicular masses, left larger than right (arrows)

homogenous with intermediate to low signal intensity on T2-weighted images and associated diffusion restriction.

Central nervous system involvement is also more common in sporadic and immunodeficiencyassociated $\mathrm{BL}$. BL of the CNS is seen in up to $15 \%$ of cases at presentation, is a common complication of recurrent or treatment resistant disease, and is associated with a worse prognosis [41]. CNS BL presents anywhere along the neuroaxis including within the brain and spinal canal and may present as a discrete mass or areas of leptomeningeal thickening (Fig. 12). However, even if CNS involvement is not apparent on imaging, lumbar puncture is necessary to exclude CNS BL.

\section{Bone marrow}

$\mathrm{BL}$ of the bone marrow is seen in approximately $30 \%$ of cases at presentation and, similar to CNS involvement, is seen in recurrent or treatment resistant disease, confers an advanced stage of disease, and associated with worse prognosis (Fig. 13) [41, 42]. On radiography and CT, lymphoma appears as a permeative lytic lesion with associated periosteal reaction and cortical destruction. On MRI, bone marrow involvement manifests as focal or diffuse areas of marrow replacement by low signal on T1-weighted images with associated increased T2 signal intensity. MRI often is better able to depict an associated soft tissue mass, if present. While BL of the bone marrow is often seen in the setting of bulky disease elsewhere, a subset of patients presents with bone marrowand blood-predominant or exclusive disease, which is termed Burkitt leukemia and considered a variant of Burkitt lymphoma in the 2016 WHO classification [10]. Burkitt leukemia patients with isolated bone marrow involvement have a better prognosis compared to $\mathrm{BL}$ patients with bone marrow involvement when treated similarly [43]. Analogous to BL of the CNS, bone marrow biopsy is necessary to exclude bone marrow involvement not visible on imaging.

\section{Treatment}

Chemotherapy is the mainstay of therapy in BL (Fig. 14). Given the effectiveness of chemotherapy regimens and often widespread disease at presentation, there is no role for radiation therapy. Similarly, even in localized cases, surgery is generally not pursued unless disease complications necessitate prompt surgical intervention such as in cases of bowel obstruction [44]. The approach to therapy in the different subtypes of BL is similar. 


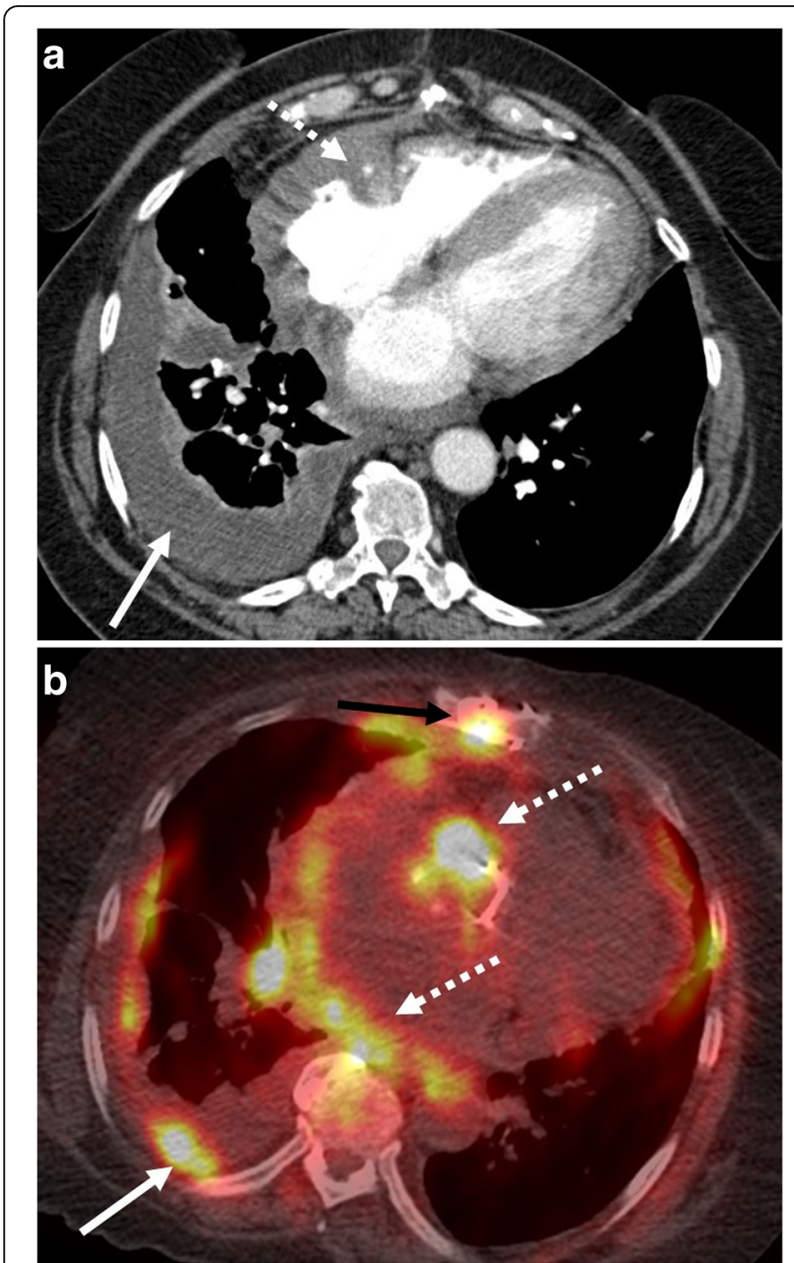

Fig. 9 Pleural and pericardial involvement. A 62-year-old female presenting with chest pain and shortness of breath. a Contrastenhanced axial $\mathrm{CT}$ image demonstrates a partially loculated right pleural effusion (solid arrow) and mass-like thickening of the pericardium extending into the epicardial fat encasing the right coronary artery (dashed arrow). b Fused axial PET-CT demonstrates associated hypermetabolic uptake within the pericardial mass (white dashed arrows) and better depicts multifocal right-sided pleural involvement (white solid arrow). There is also sternal involvement (black solid arrow)

\section{Treatment protocols}

Given the lack of randomized control trials, there is currently no clear choice of therapy in BL. Furthermore, most adult $\mathrm{BL}$ regimens are based on pediatric clinical trials. Current treatment regimens, either short or longer duration, employ intensive, multi-agent regimens composed of doxorubicin, alkylators, vincristine, and etoposide [45]. Less intensive regimens (i.e., CHOP-based therapies) used in other subtypes of non-Hodgkin lymphoma have been associated with higher rates of disease relapse [46]. Many current regimens incorporate the use of rituximab, often starting in the second cycle
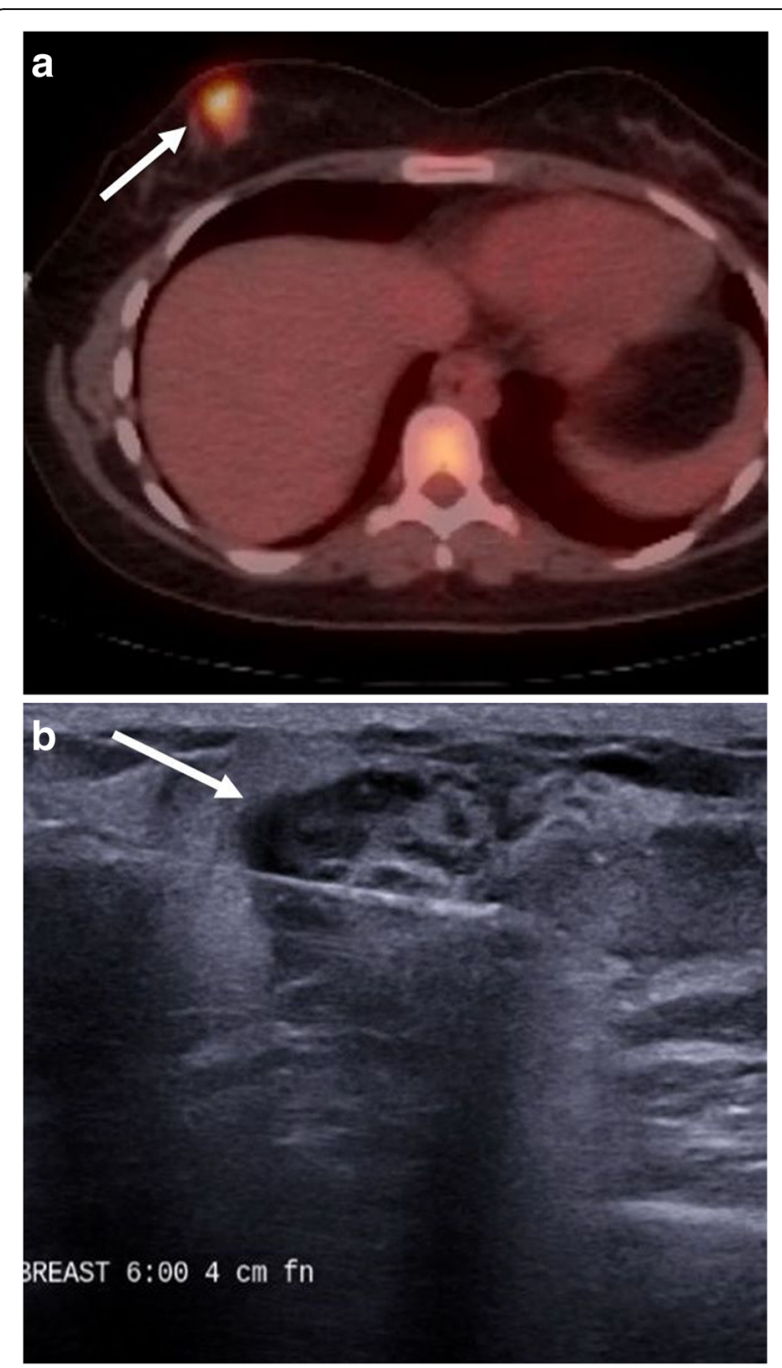

Fig. 10 Breast involvement. A 22-year-old female with known Burkitt lymphoma. a Staging fused axial PET-CT demonstrates hypermetabolic activity within the inferior and medial right breast (arrow). b Grayscale ultrasound during percutaneous biopsy demonstrates an irregular, heterogeneous mass with indistinct margins (arrow). Biopsy results revealed Burkitt lymphoma

to minimize adverse therapy effects. In a multi-center trial of 260 patients with median follow-up of 38 months, Ribrag et al. demonstrated improved event free $(75 \%$ vs $62 \%$ ) and overall ( $83 \%$ vs $70 \%$ ) survival at 3 years without significant difference in adverse events [47]. CNS prophylaxis with intrathecal methotrexate and/ or cytarabine is also a component of first-line therapy given high risk of CNS involvement in $\mathrm{BL}$ patients. Without CNS prophylaxis, between 30 and $50 \%$ will develop CNS relapse, often within the first year, with rates decreasing to $6-11 \%$ with CNS prophylaxis [48-50]. 


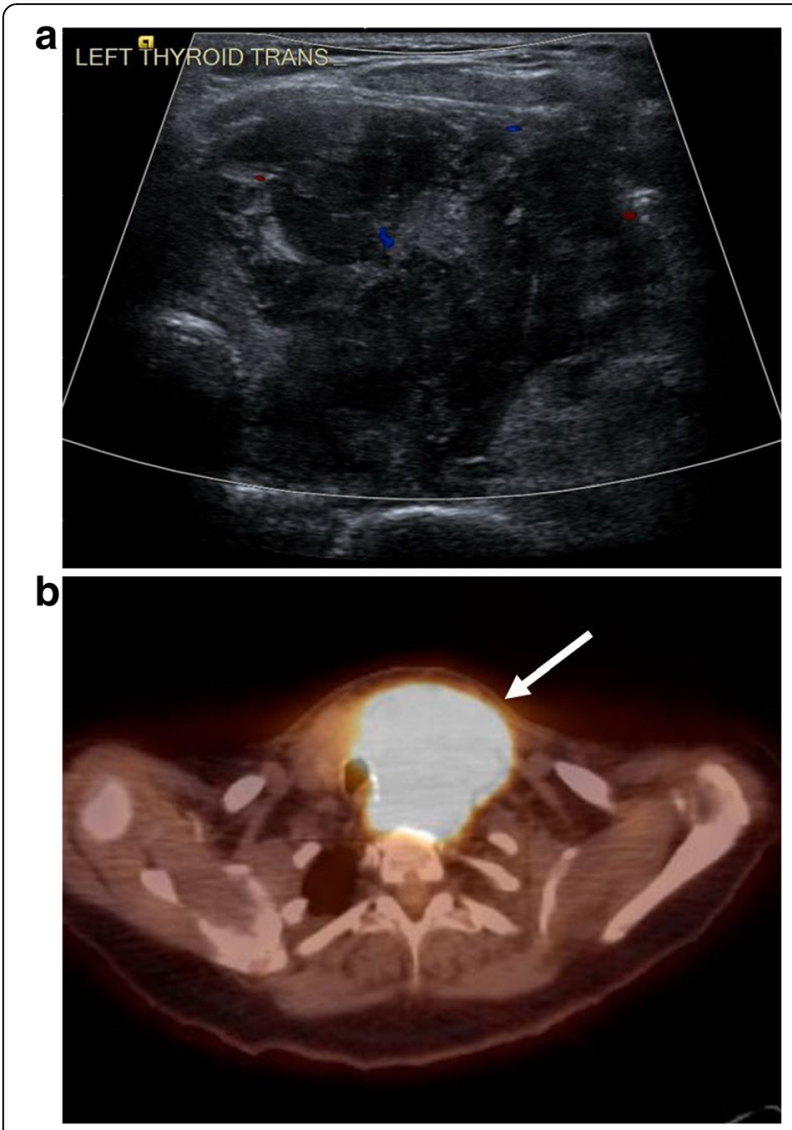

Fig. 11 Thyroid involvement. A 58-year-old female presenting with dysphagia. a Transverse color Doppler image through the left thyroid demonstrates a large, heterogeneous hypovascular mass. b Fused axial PET-CT demonstrates the thyroid mass with rightward tracheal displacement and associated hypermetabolic activity. Biopsy of the thyroid mass revealed Burkitt lymphoma

\section{Surveillance and refractory disease}

Following initiation of therapy, patients are followed regularly and assessed via history, physical examination, and laboratory studies including complete blood count, lactate dehydrogenase, and biochemical profile. In adults, imaging surveillance with CT is performed, as described previously. In children, routine surveillance with cross-sectional imaging may not be warranted for patient achieving complete response after therapy given overall low rates of relapse along with increased costs and added risks of radiation exposure [51]. Thus, surveillance may be performed with cervical and abdominal ultrasound with chest radiography with $\mathrm{CT}$ or $\mathrm{PET} / \mathrm{CT}$ reserved if there are signs of relapse. Given recent advances in therapy, the overall survival in $\mathrm{BL}$ has continued to improve. Patients less than 19 years old have the best prognosis with $87 \%$ 5-year survival for diagnoses between
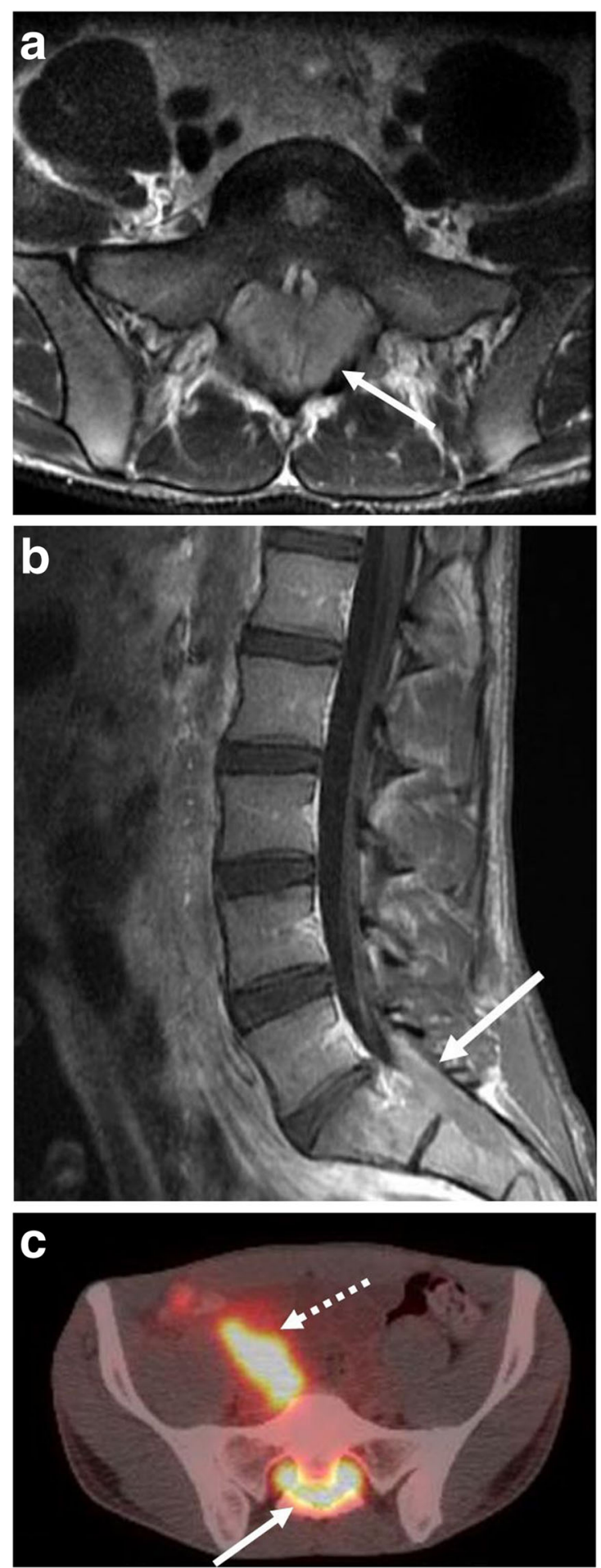

Fig. 12 Central nervous system involvement. A 24-year-old male presenting with abdominal and lower back pain. a Axial T2-weighted and (b) sagittal post contrast images of the lumbar spine and sacrum demonstrate an enhancing soft tissue mass within the lower spinal canal (arrows) with extension into bilateral sacral neural foramina. c Fused axial PET-CT demonstrates associated hypermetabolic activity within the sacral mass (solid arrow). Involvement of the right retroperitoneum is also seen (dashed arrow) 


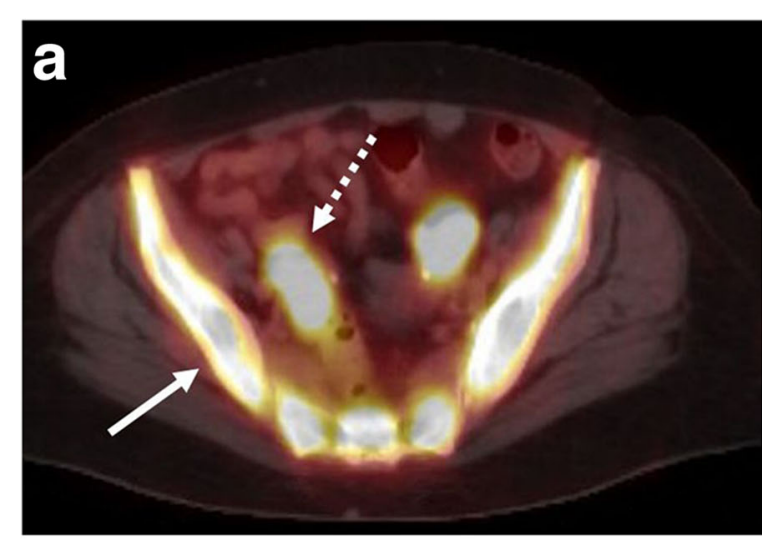

$$
\text { b }
$$
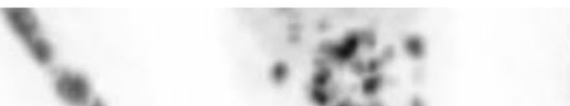
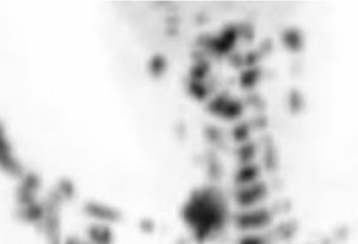

T.

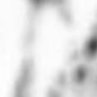

.
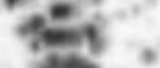

$\cos ^{2}$
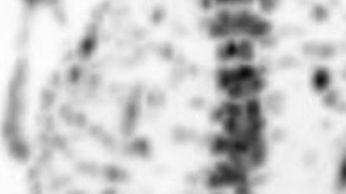

$-\frac{3}{3}$

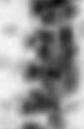

*
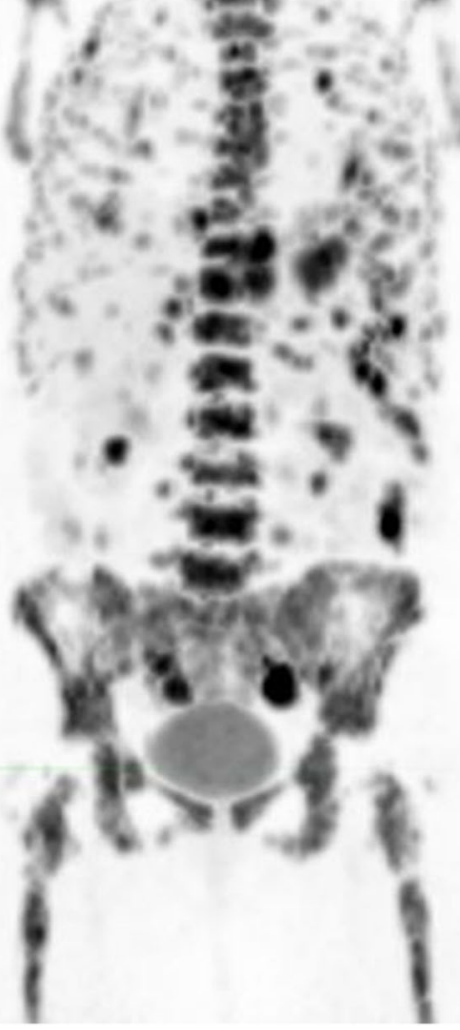$$
\text { etives. }
$$
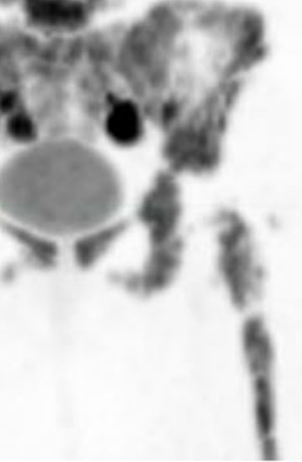

Fig. 13 Diffuse marrow involvement. A 74-year-old female with known Burkitt lymphoma. a Fused axial PET-CT demonstrates diffuse hypermetabolic activity within the visualized marrow of the pelvis (solid arrow). Soft tissue activity is also seen within the pelvis (dashed arrow). b Whole body planar PET image demonstrates both diffuse marrow and soft tissue disease within the lower neck, thorax, abdomen, and pelvis
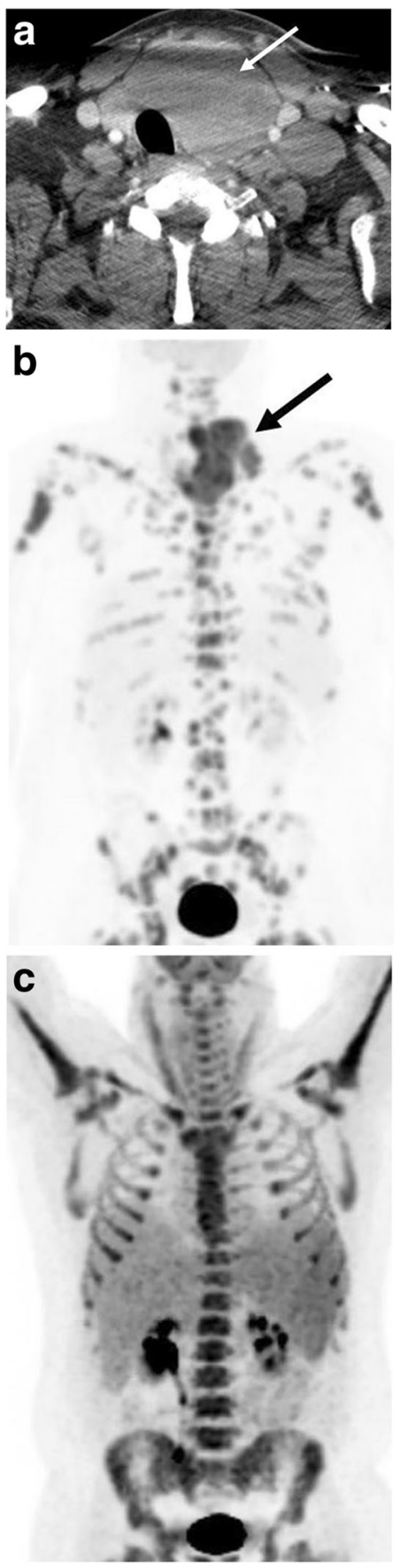

Fig. 14 Treatment response. A 42-year-old man initially presenting with neck mass and constitutional symptoms. Contrast-enhanced axial CT at presentation (a) demonstrates a large left neck mass (arrow) replacing the left thyroid with tracheal deviation. b Staging whole body planar PET image demonstrates a hypermetabolic left lower neck mass (arrow) and heterogeneous marrow involvement. The patient underwent R-CHOP with intrathecal methotrexate, 4 cycles of hyper-CVAD and intrathecal methotrexate. Follow-up (c) whole-body planar PET image imaging show resolution of the cervical mass without evidence of distant disease. Diffuse homogeneous marrow uptake on the PET scan is likely related to post-therapy marrow activation 
a

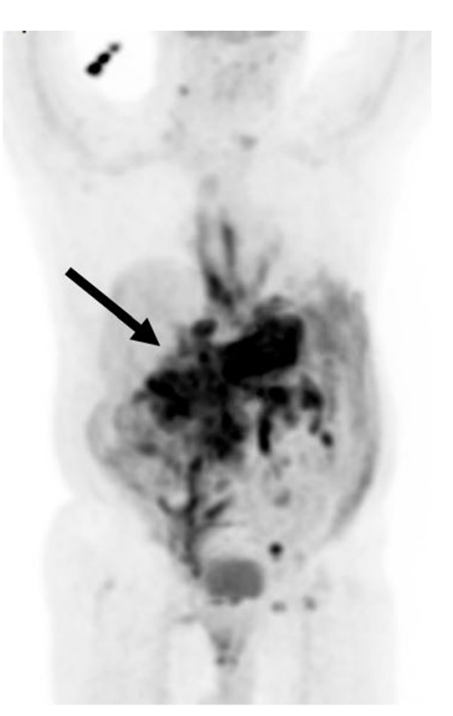

C

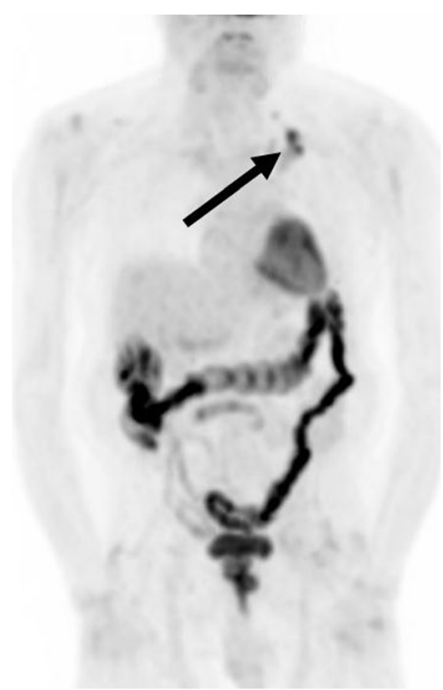

b

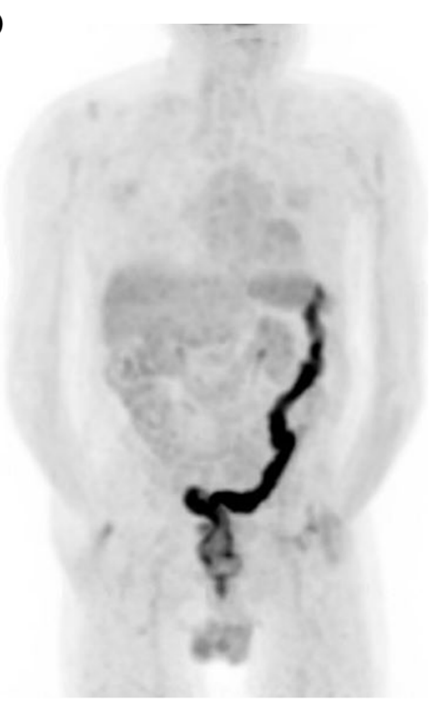

d

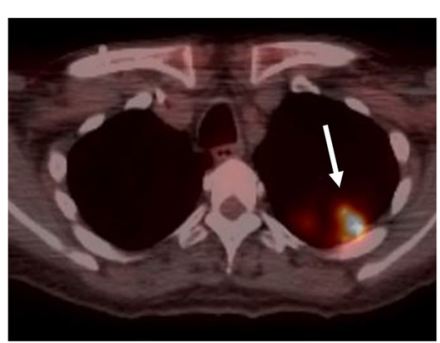

Fig. 15 Pulmonary recurrence. An 83-year-old man initially presenting with Gl bleeding and was found to have conglomerate gastric and intra-abdominal masses. a Initial staging whole body planar PET image demonstrates extensive abdominal disease involvement (arrow). He went on to complete 4 cycles of bendamustine and rituximab. b Follow-up whole body planar PET image demonstrates complete disease response. c A subsequent restaging whole body planar PET image demonstrates a new hypermetabolic focus within the left upper thorax (arrow). d Corresponding fused axial PET-CT demonstrates a pleural-based lesion (arrow). Percutaneous biopsy revealed Burkitt lymphoma

2002 and 2008, while older patients and those advanced disease have the worst prognosis. For example, BL patients diagnosed after the age of 60 years have a 5-year survival rate of 33\% [52].

Patients with relapsed disease usually present symptomatically and within the first year after the completion of treatment. Relapsed disease may occur at the sites of original presentation or remotely (Fig. 15). Currently, no prospective studies have evaluated therapy regimens in relapsed patients, and patients who have failed first-line therapy often undergo salvage chemotherapy as a part of clinical trials [45]. Relapsed patients may also undergo autologous stem cell transplantation [53].

\section{Treatment-related complications}

Given the high dose, intensive chemotherapy regimens employed during $\mathrm{BL}$, treatment-related toxicities and complications are commonly encountered clinically. Regardless of treatment regimen, tumor lysis syndrome (TLS) is a potential complication of therapy due to rapid growth rates of tumor cells. TLS is caused by release of cellular products overwhelming the kidneys' excretory capacity, leading to 

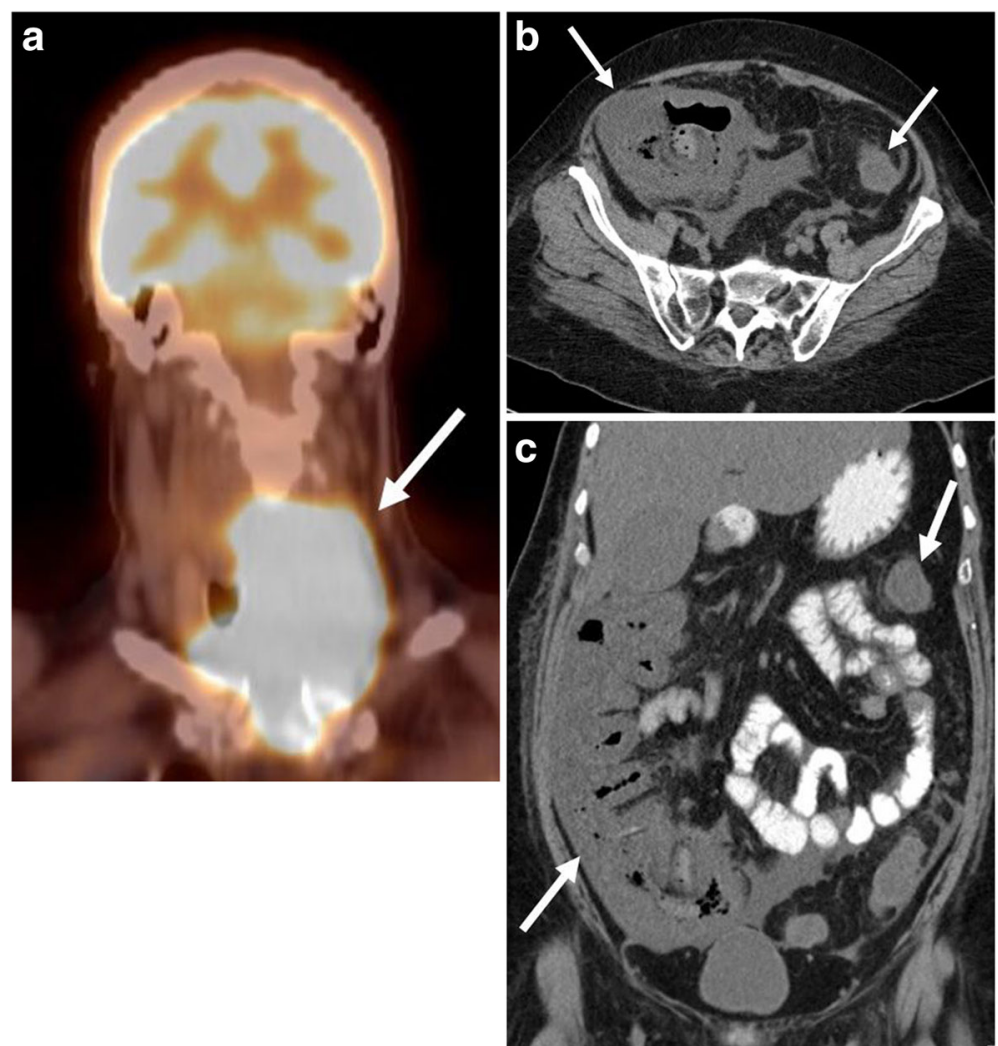

Fig. 16 Treatment-related neutropenic colitis. A 58-year-old male initially presenting with a left neck mass. a Coronal fused PET-CT demonstrates a large, hypermetabolic left neck mass (arrow) causing tracheal deviation. The mass was subsequently biopsied as Burkitt lymphoma, and the patient was subsequently started on hyper-CVAD therapy. After cycle \#3, the patient was admitted for abdominal pain and neutropenic fever. $\mathbf{b}$ Axial and (c) coronal non-contrast CT images obtained in the emergency department show diffuse colonic wall thickening and inflammatory stranding (arrows). Findings are consistent with treatment-related colitis

electrolyte imbalances including hyperkalemia, hyperphosphatemia, hyperuricemia, and ultimately renal failure. Prophylaxis and treatment of TLS include intravenous hydration, use of hypouricemic agents such as allopurinol and rasburicase, and, when indicated, dialysis. Furthermore, complications specific to various chemotherapeutic agents and regimens may also arise during treatment, many of which may be detected on imaging. For example, methotrexate is associated with pneumonitis presenting as intestinal and airspace infiltrates. Neutropenic colitis may manifest with any agent causing severe neutropenia, which presents with colonic wall thickening and edema typically affecting the cecum and ascending colon (Fig. 16). Cyclophosphamide is associated with the development of hemorrhagic cystitis, which appears as diffuse thickening and nodularity of the bladder wall [54].

\section{Conclusion}

$\mathrm{BL}$ is a highly aggressive, rapidly growing $\mathrm{B}$ cell non-Hodgkin lymphoma. BL has a very heterogeneous pattern of presentation and clinical course. Given the diverse nature of disease involvement, multiple imaging modalities play a key role in Burkitt lymphoma evaluation throughout the entire disease course, each with certain advantages and disadvantages. Furthermore, radiologists should recognize common and atypical presentations and sites of disease to appropriately guide clinicians given the urgency of potential treatment.

\section{Abbreviations}

BL: Burkitt lymphoma; CNS: Central nervous system; CT: Computed tomography; DLBCL: Diffuse large B cell lymphoma; DWI: Diffusion-weighted imaging; EBV: Epstein-Barr virus; MUGA: Multigated; NCCN: National Comprehensive Cancer Network; NHL: Non-Hodgkin lymphoma;

PET: Positron emission tomography; SUV: Standardized uptake value; TLS: Tumor lysis syndrome; WHO: World Health Organization

\section{Acknowledgements}

Not applicable

Funding

The authors declare that this study has not received any funding. 


\section{Availability of data and materials}

Data sharing is not applicable to this article as no datasets were generated or analyzed during the current study.

\section{Authors' contributions}

FC analyzed and interpreted the patient data regarding the hematological disease and the transplant. RH performed the histological examination of the kidney, and was a major contributor in writing the manuscript. All authors read and approved the final manuscript.

\section{Ethics approval and consent to participate}

Not applicable

\section{Consent for publication}

Not applicable

\section{Competing interests}

The authors declare that they have no competing interests.

\section{Publisher's Note}

Springer Nature remains neutral with regard to jurisdictional claims in published maps and institutional affiliations.

\begin{abstract}
Author details
'Department of Radiology, Duke University, Durham, NC, USA. ${ }^{2}$ Department of Imaging, Dana Farber Cancer Institute, Harvard Medical School, 450 Brookline Avenue, Boston, MA 02215, USA. 'Department of Radiology, Brigham and Women's Hospital, Harvard Medical School, Boston, MA, USA. ${ }^{4}$ Department of Pathology, UH Cleveland Medical Center, Case Western Reserve University, Cleveland, OH, USA. ${ }^{5}$ Department of Radiology, UH Cleveland Medical Center, Case Western Reserve University, Cleveland, $\mathrm{OH}$, USA.
\end{abstract}

\section{Received: 15 January 2019 Accepted: 13 March 2019}

\section{Published online: 21 May 2019}

\section{References}

1. Mbulaiteye SM, Anderson WF, Ferlay J et al (2012) Pediatric, elderly, and emerging adult-onset peaks in Burkitt's lymphoma incidence diagnosed in four continents, excluding Africa. Am J Hematol 87(6):573-578. https://doi.org/10.1002/ajh.23187

2. Morton LM, Wang SS, Devesa SS, Hartge P, Weisenburger DD, Linet MS (2006) Lymphoma incidence patterns by WHO subtype in the United States, 1992-2001. Blood 107(1):265-276. https://doi.org/10.1182/blood2005-06-2508

3. Ferry JA (2006) Burkitt's lymphoma: clinicopathologic features and differential diagnosis. Oncologist 11(4):375-383. https://doi.org/10.1634/ theoncologist.11-4-375

4. Ogwang MD, Bhatia K, Biggar RJ, Mbulaiteye SM (2008) Incidence and geographic distribution of endemic Burkitt lymphoma in northern Uganda revisited. Int J Cancer 123(11):2658-2663. https://doi.org/10.1002/ijc.23800

5. Magrath I (2012) Epidemiology: clues to the pathogenesis of Burkitt lymphoma. Br J Haematol 156(6):744-756. https://doi.org/10.1111/j.13652141.2011.09013.x

6. Brady G, MacArthur GJ, Farrell PJ (2007) Epstein-Barr virus and Burkitt lymphoma. J Clin Pathol 60(12):1397-1402. https://doi.org/10.1136/jcp. 2007.047977

7. Schmitz R, Ceribelli M, Pittaluga S, Wright G, Staudt LM (2014) Oncogenic mechanisms in Burkitt lymphoma. Cold Spring Harb Perspect Med 4(2). https://doi.org/10.1101/cshperspect.a014282

8. O'Malley DP, Auerbach A, Weiss LM (2015) Practical applications in immunohistochemistry: evaluation of diffuse large B-cell lymphoma and related large B-cell lymphomas. Arch Pathol Lab Med 139(9):1094-1107. https://doi.org/10.5858/arpa.2014-0451-CP

9. Sesques P, Johnson NA (2017) Approach to the diagnosis and treatment of high-grade B-cell lymphomas with MYC and BCL2 and/or BCL6 rearrangements. Blood 129(3):280-288. https://doi.org/10.1182/ blood-2016-02-636316

10. Swerdlow SH, Campo E, Pileri SA et al (2016) The 2016 revision of the World Health Organization classification of lymphoid neoplasms. Blood 127(20): 2375-2390. https://doi.org/10.1182/blood-2016-01-643569
11. Shawker TH, Dunnick NR, Head GL, Magrath IT (1979) Ultrasound evaluation of American Burkitt's lymphoma. J Clin Ultrasound 7(4):279-283

12. Biko DM, Anupindi SA, Hernandez A, Kersun L, Bellah R (2009) Childhood Burkitt lymphoma: abdominal and pelvic imaging findings. AJR Am J Roentgenol 192(5):1304-1315. https://doi.org/10.2214/AJR.08.1476

13. Gu J, Chan T, Zhang J, Leung AY, Kwong YL, Khong PL (2011) Whole-body diffusion-weighted imaging: the added value to whole-body MRI at initial diagnosis of lymphoma. AJR Am J Roentgenol 197(3):W384-W391. https:// doi.org/10.2214/AJR.10.5692

14. Schob S, Meyer J, Gawlitza M et al (2016) Diffusion-weighted MRI reflects proliferative activity in primary CNS lymphoma. PLoS One 11(8):e0161386. https://doi.org/10.1371/journal.pone.0161386

15. Mayerhoefer ME, Karanikas G, Kletter K et al (2015) Evaluation of diffusionweighted magnetic resonance imaging for follow-up and treatment response assessment of lymphoma: results of an 18F-FDG-PET/CT-controlled prospective study in 64 patients. Clin Cancer Res 21(11):2506-2513. https:// doi.org/10.1158/1078-0432.CCR-14-2454

16. Albano D, Bosio G, Re A, Pagani C, Giubbini R, Bertagna F (2018) Metabolic behavior and prognostic value of early and end of treatment 18F-FDG PET/ CT in adult Burkitt's lymphoma: the role of Deauville and IHP criteria. Leuk Lymphoma:1-8. https://doi.org/10.1080/10428194.2018.1482541

17. Albano D, Bosio G, Pagani C et al (2019) Prognostic role of baseline 18FFDG PET/CT metabolic parameters in Burkitt lymphoma. Eur J Nucl Med Mol Imaging 46(1):87-96. https://doi.org/10.1007/s00259-018-4173-2

18. Bailly C, Eugene T, Couec ML et al (2014) Prognostic value and clinical impact of (18) FDG-PET in the management of children with Burkitt lymphoma after induction chemotherapy. Front Med (Lausanne) 1:54. https://doi.org/10.3389/fmed.2014.00054

19. Carrillo-Cruz E, Marin-Oyaga VA, Sole Rodriguez M et al (2015) Role of 18FFDG-PET/CT in the management of Burkitt lymphoma. Eur J Haematol 94(1): 23-30. https://doi.org/10.1111/ejh.12284

20. Davidson T, Priel E, Schiby G et al (2018) Low rate of spleen involvement in sporadic Burkitt lymphoma at staging on PET-CT. Abdom Radiol (NY) 43(9):23692374. https://doi.org/10.1007/s00261-017-1454-3

21. Karantanis D, Durski JM, Lowe VJ et al (2010) 18F-FDG PET and PET/CT in Burkitt's lymphoma. Eur J Radiol 75(1):e68-e73. https://doi.org/10. 1016/j.ejrad.2009.07.035

22. Wei WX, Huang JJ, Li WY et al (2015) Prognostic values of interim and posttherapy 18F-FDG PET/CT scanning in adult patients with Burkitt's lymphoma. Chin J Cancer 34(12):608-613. https://doi.org/10.1186/s40880-015-0057-z

23. Cheng G, Servaes S, Zhuang H (2013) Value of (18) F-fluoro-2-deoxy-Dglucose positron emission tomography/computed tomography scan versus diagnostic contrast computed tomography in initial staging of pediatric patients with lymphoma. Leuk Lymphoma 54(4):737-742. https://doi.org/10 3109/10428194.2012.727416

24. Heacock L, Weissbrot J, Raad R et al (2015) PET/MRI for the evaluation of patients with lymphoma: initial observations. AJR Am J Roentgenol 204(4): 842-848. https://doi.org/10.2214/AJR.14.13181

25. Zelenetz A, Gordon L, J. A, A. R (2018) NCCN clinical practice guidelines: Bcell lymphomas version 1.2019

26. Gopal S, Gross TG (2018) How I treat Burkitt lymphoma in children, adolescents, and young adults in sub-Saharan Africa. Blood 132(3):254-263. https://doi.org/10.1182/blood-2018-04-844472

27. Burggraaff CN, de Jong A, Hoekstra OS et al (2019) Predictive value of interim positron emission tomography in diffuse large B-cell lymphoma: a systematic review and meta-analysis. Eur J Nucl Med Mol Imaging 46(1):6579. https://doi.org/10.1007/s00259-018-4103-3

28. Dunnick NR, Reaman GH, Head GL, Shawker TH, Ziegler JL (1979) Radiographic manifestations of Burkitt's lymphoma in American patients. AJR Am J Roentgenol 132(1):1-6. https://doi.org/10.2214/ajr. 132.1.1

29. England RJ, Pillay K, Davidson A, Numanoglu A, Millar AJ (2012) Intussusception as a presenting feature of Burkitt lymphoma: implications for management and outcome. Pediatr Surg Int 28(3):267-270. https://doi. org/10.1007/s00383-011-2982-5

30. Wong S, Sanchez TR, Swischuk LE, Huang FS (2009) Diffuse peritoneal Iymphomatosis: atypical presentation of Burkitt lymphoma. Pediatr Radiol 39(3):274-276. https://doi.org/10.1007/s00247-008-1063-y

31. Kluge R, Kurch L, Montravers F, Mauz-Korholz C (2013) FDG PET/CT in children and adolescents with lymphoma. Pediatr Radiol 43(4):406-417. https://doi.org/10.1007/s00247-012-2559-z 
32. Nzeh DA (1988) Atypical intrathoracic manifestations of Burkitt's lymphoma. Pediatr Radiol 18(5):411-412

33. Chan O, Igwe M, Breburda CS, Amar S (2016) Burkitt lymphoma presenting as an intracardiac mass: case report and review of literature. Am J Case Rep 17:553-558

34. Kobayashi T, Hyodo M, Honda N (2013) Primary endobronchial Burkitt's lymphoma in a child: a case report. Int J Pediatr Otorhinolaryngol 77(5):875878. https://doi.org/10.1016/j.jporl.2013.03.012

35. Lu R (2012) Primary burkitt lymphoma of the chest wall. Case Rep Hematol 2012:746098. https://doi.org/10.1155/2012/746098

36. Kaul P, Javangula K (2007) Burkitt lymphoma masquerading as cardiac tamponade. J Cardiothorac Surg 2:30. https://doi.org/10.1186/1749-8090-2-30

37. Janbabai G, Kayedimajd S, Alian S, Naghshvar F, Rashidi M, Farazmandfar T (2012) Bilateral breast swelling in a 23-year-old woman with Burkitt lymphoma. J Res Med Sci 17(12):1188-1191

38. Dozzo M, Carobolante F, Donisi PM et al (2017) Burkitt lymphoma in adolescents and young adults: management challenges. Adolesc Health Med Ther 8:11-29. https://doi.org/10.2147/AHMT.S94170

39. Derinkuyu BE, Boyunaga O, Oztunali C et al (2016) Imaging features of Burkitt lymphoma in pediatric patients. Diagn Interv Radiol 22(1):95-100. https:/doi.org/10.5152/dir.2015.15211

40. Allaoui M, Benchafai I, Mahtat el M et al (2016) Primary Burkitt lymphoma of the thyroid gland: case report of an exceptional type of thyroid neoplasm and review of the literature. BMC Clin Pathol 16:6. https://doi.org/10.1186/ s12907-016-0028-6

41. Blum KA, Lozanski G, Byrd JC (2004) Adult Burkitt leukemia and lymphoma. Blood 104(10):3009-3020. https://doi.org/10.1182/blood-2004-02-0405

42. Cheson BD, Fisher RI, Barrington SF et al (2014) Recommendations for initial evaluation, staging, and response assessment of Hodgkin and non-Hodgkin lymphoma: the Lugano classification. J Clin Oncol 32(27):3059-3068. https:// doi.org/10.1200/JCO.2013.54.8800

43. Song JY, Venkataraman G, Fedoriw Y et al (2016) Burkitt leukemia limited to the bone marrow has a better prognosis than Burkitt lymphoma with bone marrow involvement in adults. Leuk Lymphoma 57(4):866-871. https://doi. org/10.3109/10428194.2015.1085529

44. Stein JE, Schwenn MR, Jacir NN, Harris BH (1991) Surgical restraint in Burkitt's lymphoma in children. J Pediatr Surg 26(11):1273-1275

45. Jacobson C, LaCasce A (2014) How I treat Burkitt lymphoma in adults. Blood 124(19):2913-2920. https://doi.org/10.1182/blood-2014-06-538504

46. Smeland S, Blystad AK, Kvaloy SO et al (2004) Treatment of Burkitt's/Burkittlike lymphoma in adolescents and adults: a 20-year experience from the Norwegian radium hospital with the use of three successive regimens. Ann Oncol 15(7):1072-1078. https://doi.org/10.1093/annonc/mdh262

47. Ribrag V, Koscielny S, Bosq J et al (2016) Rituximab and dose-dense chemotherapy for adults with Burkitt's lymphoma: a randomised, controlled, open-label, phase 3 trial. Lancet 387(10036):2402-2411. https://doi.org/10. 1016/S0140-6736(15)01317-3

48. Hill QA, Owen RG (2006) CNS prophylaxis in lymphoma: who to target and what therapy to use. Blood Rev 20(6):319-332. https://doi.org/10. 1016/j.blre.2006.02.001

49. Bernstein Jl, Coleman CN, Strickler JG, Dorfman RF, Rosenberg SA (1986) Combined modality therapy for adults with small noncleaved cell lymphoma (Burkitt's and non-Burkitt's types). J Clin Oncol 4(6):847-858. https://doi.org/10.1200/JCO.1986.4.6.847

50. Sariban E, Edwards B, Janus C, Magrath I (1983) Central nervous system involvement in American Burkitt's lymphoma. J Clin Oncol 1(11):677-681. https://doi.org/10.1200/JCO.1983.1.11.677

51. Eissa HM, Allen CE, Kamdar K et al (2014) Pediatric Burkitt's lymphoma and diffuse B-cell lymphoma: are surveillance scans required? Pediatr Hematol Oncol 31(3):253-257. https://doi.org/10.3109/08880018.2013.834400

52. Costa LJ, Xavier AC, Wahlquist AE, Hill EG (2013) Trends in survival of patients with Burkitt lymphoma/leukemia in the USA: an analysis of 3691 cases. Blood 121(24):4861-4866. https:/doi.org/10.1182/blood-2012-12-475558

53. Kim H, Park ES, Lee SH et al (2014) Clinical outcome of relapsed or refractory Burkitt lymphoma and mature B-cell lymphoblastic leukemia in children and adolescents. Cancer Res Treat 46(4):358-365. https://doi.org/10, 4143/crt.2013.047

54. Torrisi JM, Schwartz LH, Gollub MJ, Ginsberg MS, Bosl GJ, Hricak H (2011) CT findings of chemotherapy-induced toxicity: what radiologists need to know about the clinical and radiologic manifestations of chemotherapy toxicity. Radiology 258(1):41-56. https://doi.org/10.1148/radiol.10092129

\section{Submit your manuscript to a SpringerOpen ${ }^{\circ}$ journal and benefit from:}

- Convenient online submission

- Rigorous peer review

- Open access: articles freely available online

- High visibility within the field

- Retaining the copyright to your article

Submit your next manuscript at $\boldsymbol{\nabla}$ springeropen.com 